\title{
Research on Students Basic Information Query System Based on HTML5 Cross Platform
}

\author{
Qiang Chen ${ }^{1, a^{*}}$ and Jiajia $\mathrm{Wu}^{2, \mathrm{~b}}$ \\ ${ }^{1}$ Suzhou Industrial Park Institute Of Services Outsourcing College, Suzhou, Jiangsu, China \\ ${ }^{2}$ Suzhou Industrial Park Industrial Technology School, Suzhou, Jiangsu, China \\ achenq@siso.edu.cn, bwjj@sipits.cn \\ ${ }^{*}$ corresponding author
}

Keywords: Information query system; HTML5; Cross paltform

\begin{abstract}
Traditional PC is not convenient for students managment teacher. And native smart phone including android and ios is high cost of development. This paper analysis design and implement HTML5 coross platform students basic information query system. It help studnet mangement teach quickly get student baisc information.
\end{abstract}

\section{Introduction}

College student management teachers often encounter the querying students basic information of students is not convenient. The basic information includes the student's telephone number, dormitory number and parents' emergency contact information. At present, some college student management teachers are still to fill in the paper or Excel basic students information. Or some colleges and universities use the web information management system to record the basic information of students.

Paper or Excel is not easy to query student information leads to low efficiency. Traditional web management system student management teachers must operate in front of the computer. The student management work site is often in the dormitory or playground without computer operation scene. In practice, it is also found that when the student management workers have an emergency call, according to the existing system to read the phone and then call. Another example of student management workers in-depth interviews in the dormitory. Due to the large number of students and forget the number of student hostels, this time can quickly find the number of quarters is particularly important. For freshmen to school, student management teachers hard to identify each new student quickly. These problems are to reduce the work efficiency of college student management.

In order to solve the above problems, this paper designs and develops the basic information inquiry system based on smart phone. Currently, the smart phone platform is mainly Android and IOS mobile operating system. If the native application development will extend the development cycle and development costs. Therefore, the system uses HTML5 to develop APP application, after the completion of the development were packaged into Android and IOS applications.

\section{System Requirements}

The student basic information inquiry system mainly includes three roles: the student work management teacher(instructor, teacher in charge), student, administrator. The administrator will import the new basic information into the system. Students can view all self information and modify self information. Student management teacher can view, search and manage all the information of the students. The system structure is shown in Figure 1. 


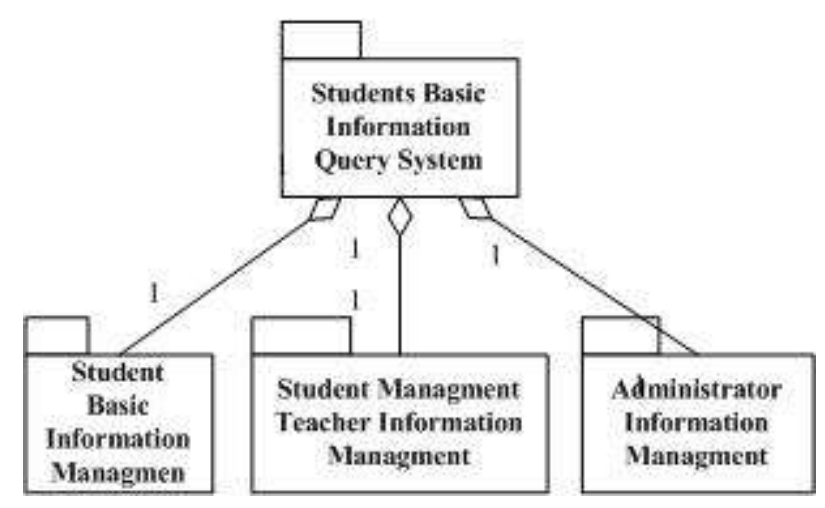

Figure 1. Student basic information system package figure

Administrator use case analysis. The main management of the basic information of students, student management staff account information and system background data management. The basic information of the students including the basic information of student enrollment, modification, deletion. The basic information of the students is defined as: students can modify the information (student phone, parents phone, home address) and students can not modify the information (student number, name, student photos, class, dormitory number). Insert, delete, modify student management information. Background maintenance mainly includes data backup and recovery, and students can modify the information audit.

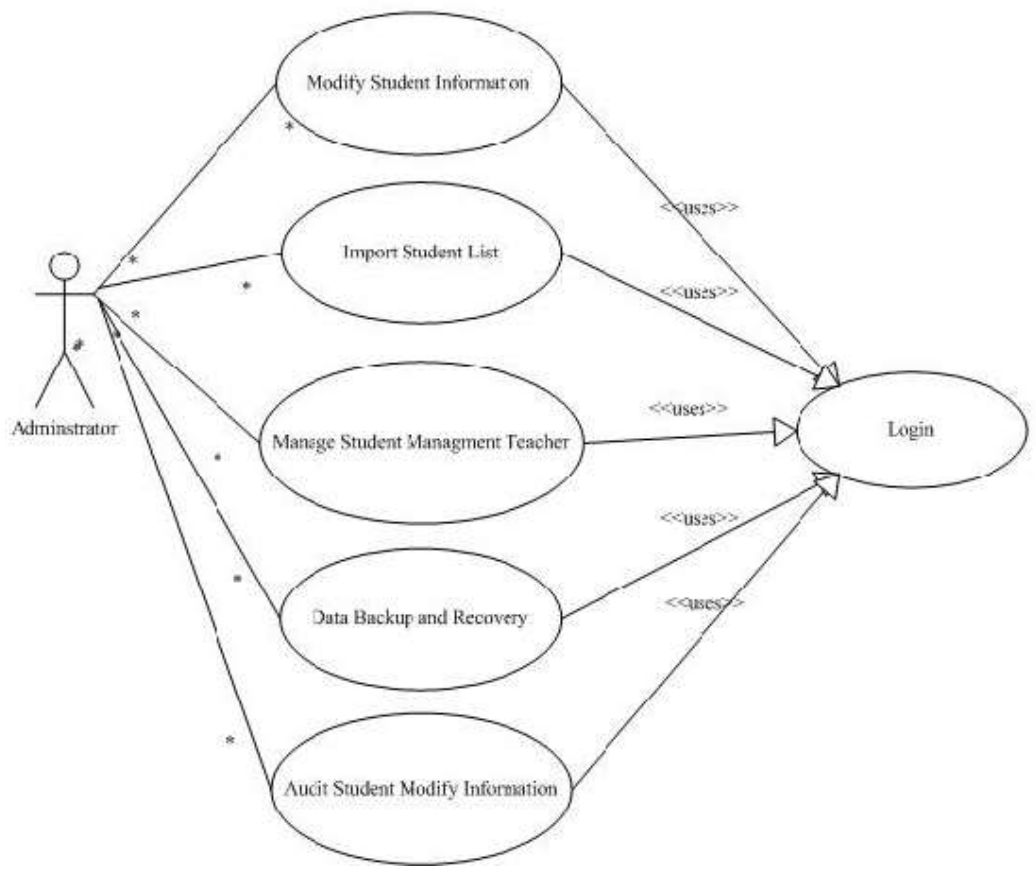

Figure 2. Administrator use case figure

Students Managment Teacher Use Case Analysis. After login Student management teacher can search student information according to student number, name, class, dormitory number and telephone inquiries. Student management teacher can view the head image and quickly identify students. Student work managers do not need to enter each student's phone number into the phone contacts. 


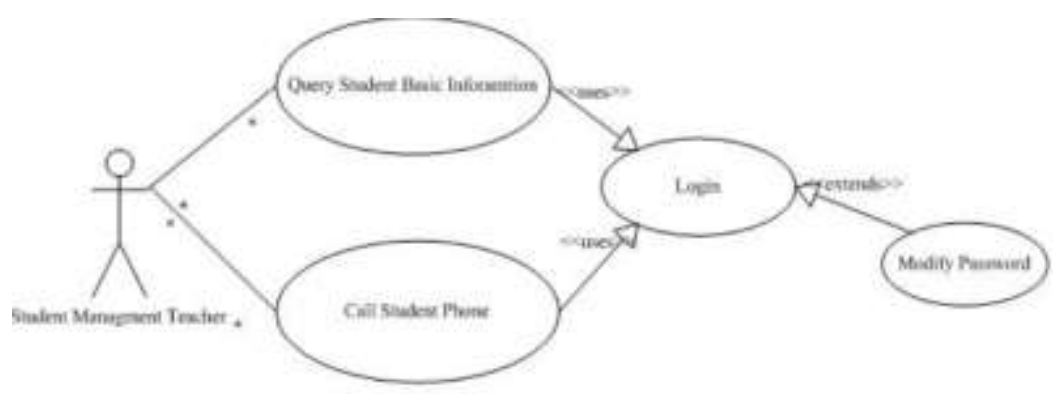

Figure 3. Administrator use case figure

Students use case analysis. After login students can view self can not modify the information, modify the information I can modify.

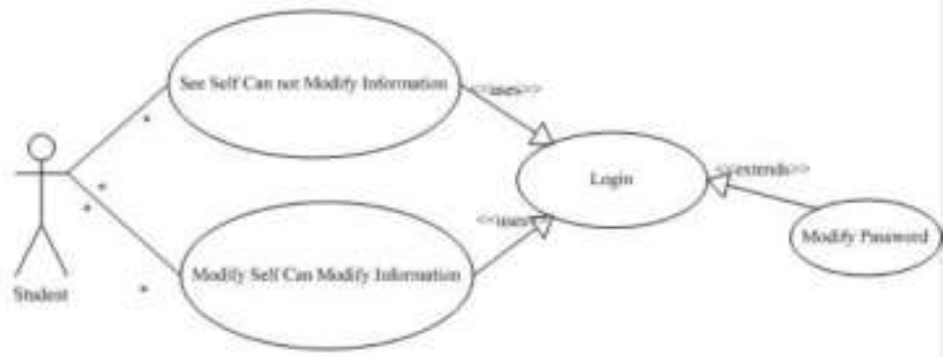

Figure 4. Student use case figure

\section{System Designs}

Overall Designs. The system server uses ThinkPHP MVC framework to develop background management logic and provide network services for smart phones. After the analysis of the operation of the system is query, in order to improve the system concurrency in the data storage layer before adding memcached. Smart phones using HTML5 development, and server communication data format using JSON.

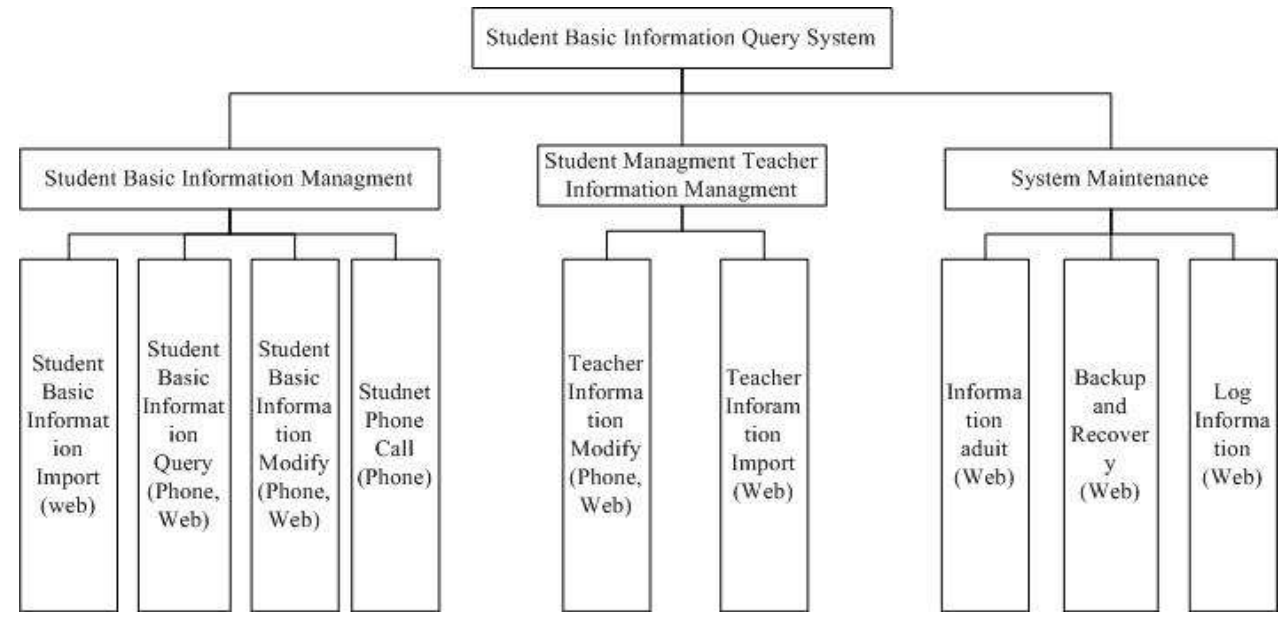

Figure 5. System function structure figure

Server database design. The database table includes, student information table field for students ID, student number, name, College (Department), professional, class, dormitory number, telephone number, parents name, parents phone, address and photo. Student management teacher table field has ID, user name, password, student management class table includes ID, class ID, management ID. The background administrator information table field includes ID, user name, password, the last login time, the class table includes ID, class name, dormitory table includes ID, dormitory name. 


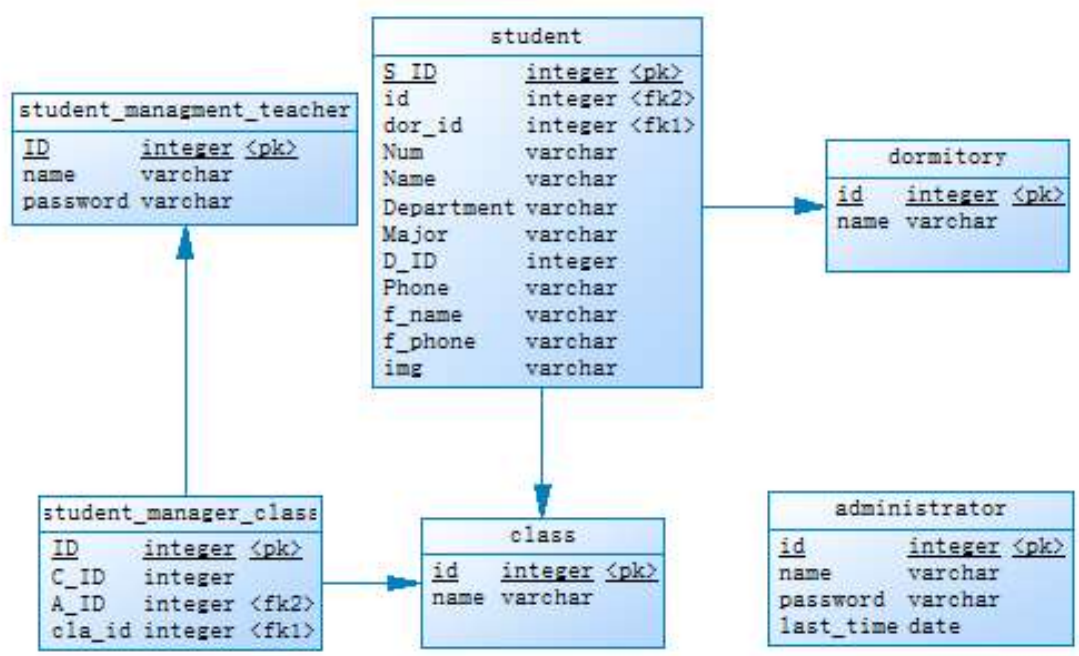

Figure 6. Data table and data relation figure

Server side design (server page design). The server uses ThinkPHP develop the business logic, the front page uses the Bootstrap and JavaScript to develop. The main background management functions as well as the mobile phone to provide data query, modify and other services. Including all teachers to increase information, delete, modify, increase, modify, delete, and bulk import operation.

Mobile terminal function design. Mobile user interface includes login, modify password, query entry page, query list display page and detailed information display page. Login page users to enter the user password automatically after the user to determine the type of display of different operating pages, users can choose to remember the password function to facilitate the next direct login. Modify the password page users enter the original password and two new password submitted after the modification. Users can query the page name, student class, dormitory number, telephone inquiries. The query results are displayed in the query list page. The "No Search Result" are displayed if it has not result. When the user clicks on an item, the page jumps to the details page. The teacher can view the photo of the students and the details of the students. The teacher can quickly dial the phone number on the page.

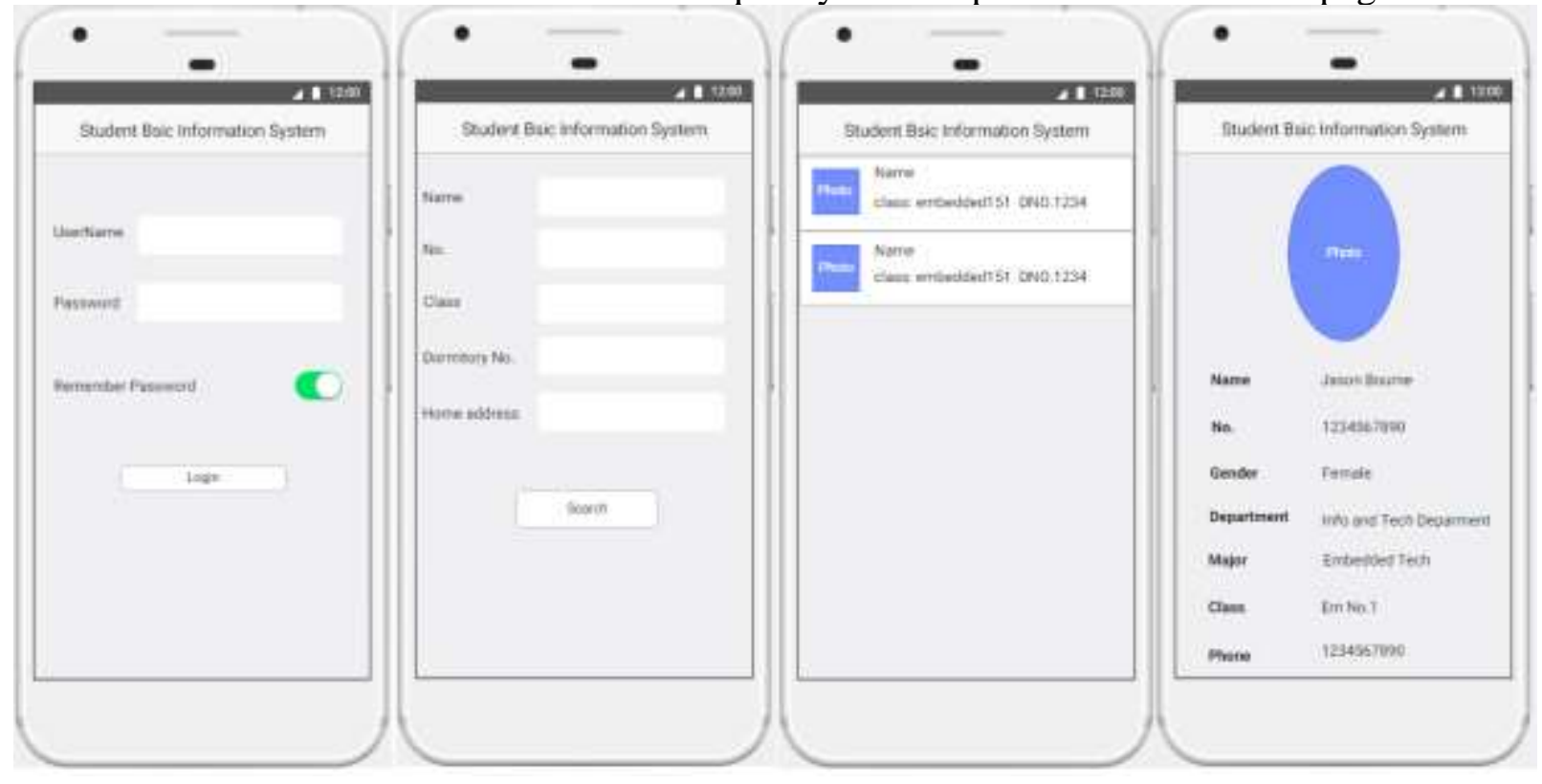

Figure 7. Mobile Design Prototype figure 


\section{system implementations}

Smart phone implementation. Smart phone using HTML5+JavaScript implementation, the use of HBuilder editor coding. Using HTML5 for mobile page layout. Use JavaScript connection server.

mui.plusReady(function() \{ //page loaded call mui.init(); //mui function init mui.getJSON(url, data, success); //network request var success $=$ function(response $)\{/ /$ network request success response $=$ JSON.stringify(response); //return JSON string and parsing students $=$ JSON.parse(response);

$\cdots$

\}

Server implementation. Server using ThinkPHP development and database using Mysql. ThinkPHP is a typical MVC framework, the use of Model layer management data, Model layer will be passed to the Control layer data processing and sent to the View layer display.

\$Username = I('login_username'); //User input username

\$Password = I('login_password'); //User input password

if (\$Username ==""||\$Password=="")\{ //Checking Username and Password

\$this -> Error('Username or Password is null'); //Report Error

\}

\$findUser['name'] = \$Username;

\$findUser['password'] = \$Password;

\$findResult = M( ' student_managment_teacher')->where(\$findUser)->find ()$; / /$ Username and Password check in database

if (! \$findResult) \{

\$findRegist['user_list_username'] = \$Username;

\$findIsRegist = M('user_list') -> where(\$findRegist) ->find(); //Check wether user register

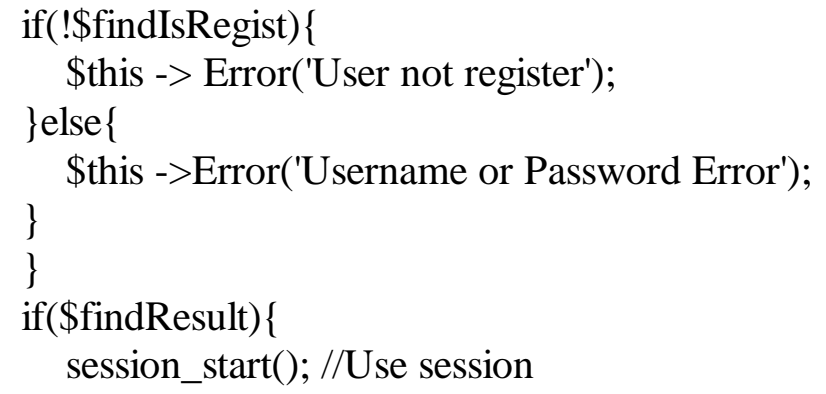

\section{Summary}

The development of smart phone based on HTML5 overcomes the problem of the traditional PC is not convenient, but also overcome the problem of developing the high cost of the original ecological development. In this way, the work efficiency is improved and the development cost is reduced. In the future to explore ways to join security to ensure data security.

\section{Acknowledgements}

The Jiangsu Province Science education project in 13th Five-Year. (No. C-c/2016/03/14); The Suzhou 13th Five-Year Educational research project. (No.SJh140). 


\section{References}

[1] Y.S.ZhangJ.MaA.Q.BaoY.Li, Design and Implementation of Student Information Management System, AMEIT 2015.

[2] Zhang Xiaojie,Lu Hanyu, Student Information Management System Design and Implementation Based on B/S, Computer Knowledge and Technology. 2013.

[3] Chen Keying, Student Information Management System Based on The Wed, Xiamen Science and Technology. 2010.

[4] Li YueYang.GuangLi Min, Application of Data Mining in the Management of College Students, ICET 2013.

[5] FU Yue, A Study of Student Information Management Software, ICOACS 2016. 